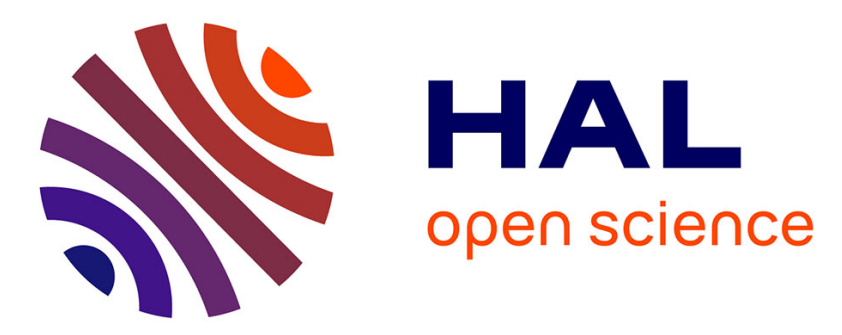

\title{
A Model for Dual Healthcare Market with Congestion Differentiation
}

\author{
Damien Besancenot, Karine Lamiraud, Radu Vranceanu
}

\section{To cite this version:}

Damien Besancenot, Karine Lamiraud, Radu Vranceanu. A Model for Dual Healthcare Market with Congestion Differentiation. 2020. hal-03028437

\section{HAL Id: hal-03028437 https://essec.hal.science/hal-03028437}

Preprint submitted on 27 Nov 2020

HAL is a multi-disciplinary open access archive for the deposit and dissemination of scientific research documents, whether they are published or not. The documents may come from teaching and research institutions in France or abroad, or from public or private research centers.
L'archive ouverte pluridisciplinaire HAL, est destinée au dépôt et à la diffusion de documents scientifiques de niveau recherche, publiés ou non, émanant des établissements d'enseignement et de recherche français ou étrangers, des laboratoires publics ou privés. 


\section{ISSEC \\ BUSINESS SCHOOL}

\section{A MODEL FOR DUAL HEALTHCARE MARKET WITH CONGESTION DIFFERENTIATION}

DAMIEN BESANCENOT, KARINE LAMIRAUD, RADU VRANCEANU

ESSEC RESEARCH CENTER

WORKING PAPER 2012

NOVEMBER 22, 2020

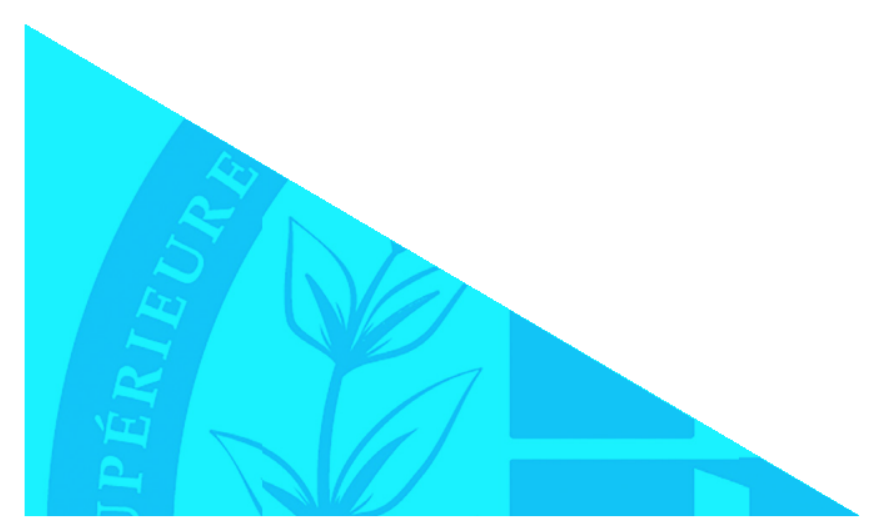


November 22, 2020

\title{
A Model for Dual Healthcare Market with Congestion Differentiation Damien Besancenot, Karine Lamiraud’ Radu Vranceanu ${ }^{\ddagger}$
}

\begin{abstract}
The French market for specialist physician care has a dual legal structure: physicians must exclusively work in sector 1 and charge regulated fees or in sector 2, where they can freely set their fees. Patient out-ofpocket payments in sector 2 are partially covered by private insurance. The primary differentiating factor between both sectors is the number of patients per specialist, which in turn directly affects the overall quality of the service provided. We built an equilibrium model to analyse both specialists' decisions about which sector to work in, and patients' choice of physician and therefore sector. More specifically, the model allowed us to study the effect of changes in prices and economy-wide patient-to-specialist ratios on profits and patients' utility associated with the services provided in each sector.
\end{abstract}

JEL Classification: D83, I11, I18.

Keywords: Dual market, Congestion, Regulation, Balance billing.

\footnotetext{
*University of Paris Descartes and LIRAES, 45 rue des Saints Pères, 75270 Paris, E-mail: damien.besancenot@parisdescartes.fr

${ }^{\dagger}$ ESSEC Business School and THEMA, 1 Av. Bernard Hirsch, 95021 Cergy, France. E-mail: lamiraud@essec.fr.

‡ESSEC Business School and THEMA, 1 Av. Bernard Hirsch, 95021 Cergy, France. E-mail: vranceanu@essec.edu
} 


\section{Introduction}

In many countries, national healthcare systems fully cover the cost of basic care while patients make out-of-pocket payments for any incremental costs related to non-basic care (e.g. additional quality of service, choosing a specific physician) (Einav et al., 2016). In this paper, we focus on France, a country where the above-mentioned principle is embedded in its dual legal market structure for specialized outpatient healthcare services.

Since 1980, self-employed specialist physicians in France have been able to choose between practicing in 'sector 1' (which is heavily regulated) or 'sector 2' (where regulation is much looser) of the dual market for specialized outpatient healthcare. In both sectors, self-employed specialists are paid on a fee-for-service basis. The essential differences between both concern the setting of fees and the levels of coverage of these fees provided by basic and complementary health insurance. The former is provided under France's National Health Insurance scheme and covers everyone living in the country, while the latter is provided by private health insurers. Specifically, sector 1 specialists agree to provide medical services at fixed regulated prices, while those working in sector 2 can choose to set their fees above the regulated price. According to Article 53 of the Public Health Law, French physicians opting to work in sector 2 should set their fees with "a degree of tact and moderation". Fees charged by sector 1 and sector 2 specialists totalled 11.9 billion euros in 2017, of which 1.7 billion euros were balance billing amounts charged by sector 2 specialists.

Basic insurance reimburses $70 \%$ of the regulated price (i.e., the price charged by sector 1 physicians) minus a one-euro co-payment. For those who have complementary insurance, the difference (i.e., $30 \%$ co-insurance in basic insurance) is fully covered but not the one-euro co-payment. In 2018, over $95 \%$ of the French population were covered by complementary insurance (DRESS, 2019). ${ }^{1}$ Complementary insurance covers the same services covered by basic insurance and can reimburse co-payments/co-insurance in basic insurance except for the one-euro co-payment. How-

\footnotetext{
${ }^{1}$ In this paper, we will assume that $100 \%$ of the French population is covered by complementary insurance.
} 


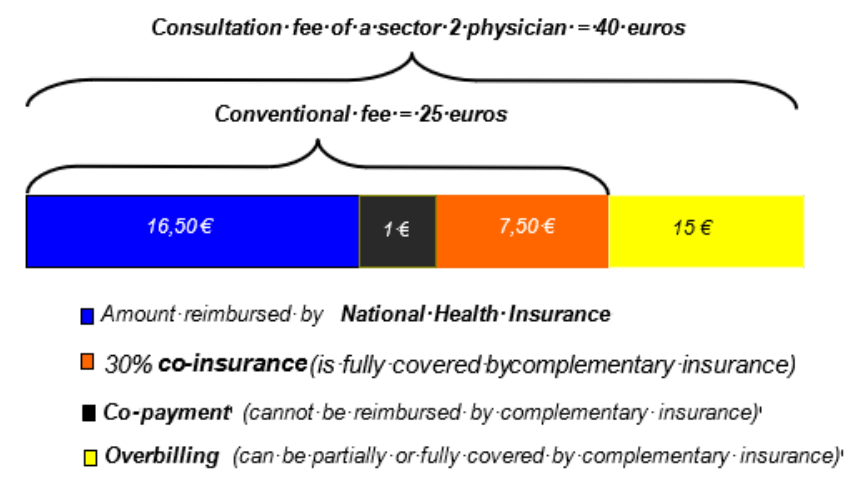

Figure 1: Payment structure of the sector 2 fee

ever, complementary insurance contracts differ greatly with respect to the coverage they offer for balance billing amounts (i.e., amounts above the regulated price). Two types of complementary contracts exist: corporate collective contracts (provided by firms for their employees) and individual contracts (negotiated on an individual basis, mostly by self-employed people). In general, corporate contracts provide greater coverage of balance billing amounts. Half of the individual contracts taken out do not cover balance billing at all (DRESS, 2019). Accordingly, patients who consult sector 1 physicians have very low co-payments (only 1 euro), while generally their counterparts consulting sector 2 physicians have to pay larger out-of-pocket payments. Figure 1 provides an example of reimbursement for the cost of a specialist visit in sectors 1 and 2. Based on survey data from 2012, Dormont and Peron (2016) estimated out-of-pocket payments for sector 2 amounted to 439 euros per patient per year.

Patients (irrespective of the type of complementary contract they take out) can freely choose between consulting a specialist working in sector 1 or in sector 2 . Why then would anyone pay an out-of-pocket fee for a consultation in sector 2, when consulting a specialist in sector 1 is effectively free (except for the one euro co-payment)? The differentiating factor is the quality of the service provided, defined broadly by Glazer and McGuire (1993) as: "any costly non-price attribute of health care that affects patients' valuation, including dimensions of convenience, comfort, communication about medical conditions, and other factors... In concrete terms, it is easiest to think 
of quality as the time a physician spends with a patient to conduct a procedure". This definition - which reflects the healthcare situation in France - does not suggest a difference in quality of medical care provided per se, rather substantial differences in the non-medical dimensions of the service and patient-perceived quality of care (Calcoen and van de Ven, 2019). In particular, it has been shown that sector 2 specialists perform longer consultations $(+4 \%$ in per-patient consultation time) than their sector 1 counterparts, all other things being equal (DREES, 2006). This superior quality of service is to a large extent related to the number of consultations to be made each day (Bardey et al. 2014), which we interpret in this paper as a proxy for the degree of congestion in a specialist's medical practice. Congestion increases a specialist's workload and stress, overstretches material resources and time, and ultimately leads to reduced patient satisfaction (Wilson and Childs, 2002; Hutton and Gunn, 2007).

Specialists must choose between sector 1 and sector 2 when setting up their practice and this choice is irrevocable. Hence, any change in the proportion of physicians working in both sectors is slow to occur as it depends on physicians retiring and how many new physicians enter the work market. In 2018, $47 \%$ of all specialists providing outpatient services in France were operating in sector 2 (compared with $43 \%$ in 2014). Why would any specialist choose to work in the heavily regulated sector 1 , when working in sector 2 affords them much more freedom in terms of setting prices? Because the number of patient per physician is larger in sector 1 compared to sector 2, which might offset the price effect. Furthermore, physicians in sector 1 get a subsidy for their contribution to their pension scheme, while sector 2 physicians do not. Also, access to sector 2 is restricted to physicians with a proven high level of skill in their speciality, as attested by experience and/or prestigious degrees.

In this paper, we develop a simple two-sector model to analyze the effects of recent French healthcare policies on the patient-to-specialist ratio in each sector, on specialists' profit and patients' utility. As mentioned above, the fees charged by physicians and out-of-pocket payments paid by patients differ between the two sectors. An original contribution of our analysis is the 
endogenous determination of the patient-to-physician ratio in each sector. More specifically, the equilibrium of our model is defined as a situation in which physicians and patients optimally choose their preferred sector, based on information available to them about the number of patients per specialist and about consultation fees. Accordingly, the number of patients per physician becomes the unique outcome for these choices (and must be correct in equilibrium). Patients who opt for sector 1 specialist services will only have to bear the high congestion 'cost'. Those who opt for sector 2 have a lower congestion cost, yet must make out-of-pocket payments (albeit small thanks to reimbursement). We assume that patients are heterogenous with respect to the coverage of the sector 2 extra-payment. In our model, physicians can move from one sector to another until profits are equalized between both. We analyse the consequences of varying the regulated price in sector 1 for a specific service, of setting a higher price for the same service in sector 2 , and of the real-world increase observed in the patient-to-physician ratio in France in recent years, thanks to an ongoing government policy to increase the number of physicians trained every year.

Some of our model's assumptions are restrictive. First, we assume that any price increase in the regulated sector (i.e., sector 1) will be covered in full by both basic and complementary insurance. While this is plausible for relatively small variations in the existing (low) price, it would not be sustainable for a much higher price increase. Second, we assume that all physicians in sector 2 charge the same price, and that this price is exogenous. This assumption is justified by the fact that the recent regulatory changes in France have strived to encourage sector 2 physicians to cap the fees they charge for services, through two main mechanisms. The first concerns additional tax incentives offered by the National Health Authority to those who voluntarily agree to cap their fees at no more than twice the regulated sector fee. An initial step in this direction was the introduction in 2012 of the Contract for Access to Care (Contrat d'Accès aux Soins (CAS)), which was then followed by the Controlled Pricing Practices Option (Option de Pratique Tarifaire Maîtrisée (OPTAM)) in 2017. On average, the maximum fee for a service charged by sector 2 specialists under OPTAM cannot exceed twice the regulated sector 1 fee. The second mechanism 
introduced is that complementary insurance contracts can no longer reimburse the full difference between the regulated sector 1 fee and the sector 2 specialist's fee if the latter has not signed up to OPTAM. ${ }^{2}$ More specifically, complementary insurance reimbursement cannot exceed $100 \%$ of the regulated fee when the service is provided by a non-OPTAM physician, while this value is $200 \%$ of the regulated fee when care is provided by an OPTAM member. ${ }^{3} 4$

The literature on health economics has already explored the topic of price and quality differentiation of the health care service in the "balance billing" setting, whereby physicians can charge an extra fee on top of the statutory fee. Early analyses of differentiated pricing represented the physician as a monopolist providing a service of homogenous quality who could price discriminate between patients who had different levels of willingness to pay (Mitchell and Cromwell, 1982; Zuckerman and Houlihan, 1991; Savage and Jones, 2004). In those models, balance billing could only increase the profits of physicians at the expense of patients. Feldman and Sloan (1988) argued that a monopolist physician who is subject to restrictions on balance billing would consciously or unconsciously negatively alter the quality of the service they provide to patients. Glazer and McGuire (1993) analysed monopolistic competition between two physicians who could engage in price and quality differentiation. They revealed the existence of a positive net fee that maximizes social welfare, and showed that restrictions on balance billing applied in the US in the late 1980s

\footnotetext{
2 This is part of recent French regulation on 'responsible' insurance contracts. In total, $90 \%$ of existing insurance contracts are certified as 'responsible'. However, some private insurance contracts do not cover in full even some of the moderate OPTAM fees.

3 As of September 2019, 17000 specialist physicians (i.e., $30 \%$ of sector 2 physicians) had joined the OPTAM agreement. Furthermore, the share of balance billing in total fees in sector 2 dropped from $35 \%$ in 2011 to $31.5 \%$ in 2018 (DRESS, 2019).

${ }^{4}$ Let us take the example of a consultation whose regulated (sector 1 ) price is 25 euros. Reimbursement by basic insurance is $70 \%$ of the regulated price minus a one-euro co-payment, i.e., 16.50 euros (calculation: $25 * 0.70-1$ euro). Any complementary insurance contract will reimburse the remaining amount minus the one euro co-payment, i.e. 7.50 euros. Let us assume that a sector 2 physician charges 40 euros for the same consultation. If $\mathrm{s} /$ he is an OPTAM subscriber, his/her patient will be reimbursed on the basis of the regulated price (25 euros). Hence reimbursement by basic insurance is still 16.50 euros. Under the OPTAM agreement for sector 2, complementary insurance reimburses $200 \%$ of the regulated price, i.e., 22.50 euros (calculation: $2 * 25-1-16.50=32.50$. Now, 32.50 $+16.50=49$ which is $>40$, hence complementary insurance reimburses $40-16.50-1=22.50$ euros). Therefore, the total out-of-pocket payment (i.e., including the co-payment) is one euro. If the sector 2 physician has not signed up to OPTAM, reimbursement for patients with basic insurance is still $70 \%$ of the regulated price minus the one euro co-payment. In this case, the considered regulated price is 23 euros (instead of 25 euros for OPTAM subscribers), hence basic insurance reimburses 15.10 euros (calculation: $23^{*} 0.70-1$ ). Complementary insurance reimburses 6.90 euros (calculation: $23 * 1-15.10-1$ ). The final patient out-of-pocket payment (including the co-payment) is 18 euros (calculation: $40-15.10-6.90$ ).
} 
would reduce quality of care for all patients, irrespective of whether they paid an extra fee or not. Kifmann and Scheuer (2011) used a similar framework to show that patient's welfare is higher under the balance billing system. Jelovac (2015) found that balance billing might restrict access to care for patients with heterogeneous health coverage, and therefore constituted a suboptimal policy. Gravelle et al. (2016) developed a classic model of price and quality differentiation à la Salop which is very suitable to assess the deregulated Australian market. They also used an empirical test to show that reduced competition leads to higher prices, yet has a negligible effect on quality. ${ }^{5}$

\section{Main assumptions}

Using our two-sector model, we studied how physicians, who supply the medical service, and patients, who demand the service, interact in France's dual market for specialised outpatient care.

Physicians can choose to work either in the regulated sector (sector 1) or in the sector allowing for balance billing (sector 2). In each sector, the care offer has two dimensions: i) the consultation fee and ii) the overall quality of the service provided in the broadest sense (i.e., waiting times, consultation duration, etc.), as it is assumed that the actual quality of medical care provided does not differ between the two sectors.

Let $p_{1}$ be the fee for a medical consultation in sector 1 with $p_{1} \geq 0$. This fee is regulated. Let $p_{2}$ be the fee for the same consultation in sector 2 , with $p_{2}>p_{1}$. We consider a situation in which the fee $p_{2}$ is also fixed by health care authorities. ${ }^{6}$

The overall quality of the encounter between the physician and the patient depends on the number of patients a physician must see every day. As mentioned in the introduction, having a high patient-to-physician ratio (or high 'congestion) stretches material resources and the physician's

\footnotetext{
${ }^{5}$ Other papers recognize that in many countries, physicians must charge uniform tariffs and focus on this quality differentiation issue (Godager et al., 2009; Brekke et al., 2010; Brekke et al., 2012).

${ }^{6}$ In this simple model, the specialist's profit monotonically increases in $p_{2}$. In France, recent regulatory changes have striven to encourage specialists in sector 2 to voluntarily set an upper limit on $p_{2}$ of twice the regulated fee for the same service.
} 
own time, translating into shorter consultations and consequently reduced patient satisfaction with the care provided.

Let $M$ denote the total number of specialists working in France. They choose their sector of activity in order to maximize their profit. In equilibrium, $\alpha$ is the share of physicians practicing in sector 1 , and $(1-\alpha)$ is the share of physicians practicing in sector 2 .

Let $P$ denote the total number of patients in France. They choose between consulting a sector 1 or sector 2 specialist, and seek to maximize their utility associated with the healthcare consultation provided. At equilibrium, a fraction $\nu$ of the patients will choose to consult a physician in sector 1, while $(1-\nu)$ of the patients will opt for sector 2. Patients in both sectors are distributed homogeneously among all physicians.

The number of patients per physician in each sector is therefore:

$$
\begin{aligned}
n_{1} & =\frac{v P}{\alpha M}=\frac{\nu}{\alpha} k \\
n_{2} & =\frac{(1-\nu) P}{(1-\alpha) M}=\frac{(1-\nu)}{1-\alpha} k,
\end{aligned}
$$

with the patient-to-specialist ratio $k=P / M$. The ratio can evolve for structural reasons, such as population ageing which might increase $P$, and policies that would regulate the numbers of physicians (e.g., abolishing existing quotas on higher education admissions or on immigrant specialists).

Bardey et al. (2014) point out that many scholars in healthcare and education assume that the quality of the service provided by a hospital or university depends upon provider/patient or teacher/student ratio. In this line of reasoning, we assume that, in each sector $j$, the monetary cost of patient discomfort associated with congestion is a linear function of the number of patients per specialist:

$$
c_{j}=\gamma n_{j}, \text { with } \gamma>0 \text { and } j=(1,2)
$$

Within the French context, the sector 1 fee $p_{1}$ is fully reimbursed. However, in the more expensive sector $2, p_{2}$ is only partially covered by health insurance contracts 
In sector $j$ with $j=(1,2)$, for a patient $i$, the health insurance coverage (i.e., both for basic and complementary contracts) covers a monetary amount $R_{j}^{i}$ with:

$$
R_{j}^{i}= \begin{cases}p_{1} & \text { for } j=1 \\ r^{i} & \text { for } j=2\end{cases}
$$

Although everyone in France has complementary insurance (the assumption made in our model), there is nonetheless a great deal of heterogeneity in the extent of coverage for balance billing expenses between contracts for complementary insurance (DREES, 2019). We model this heterogeneity by assuming that reimbursements $r^{i}$ are uniformly distributed over the interval $\left[p_{1}, p_{2}\right]{ }^{7}$

In this two-sector market, a patient $i$ must choose between two alternative care offers (reflecting both sectors 1 and 2), each being characterized by two dimensions: \{out-of-pocket payments and congestion costs\}:

$$
\left\{\begin{array}{l}
\text { Offer sector } 1:\left(0, c_{1}\right) \\
\text { Offer sector } 2:\left(p_{2}-r^{i}, c_{2}\right)
\end{array}\right.
$$

- Patient utility:

Denoting the monetary value of healthcare by $\bar{u}$, a patient $i$ who accepts the offer $\left(p_{j}, c_{j}\right)$ has a net utility $U_{j}^{i}$ :

$$
U_{j}^{i}=\bar{u}-\left(p_{j}-R_{j}^{i}\right)-c_{j}
$$

The patient is aware of the offers in the two sectors. S/he selects a physician in a specific sector in order to maximize his/her utility $U^{i}$.

- Physician profit:

In their professional activity, each doctor bears a cost per patient $q$. To keep the analysis as simple as possible, we do not take into account the fixed cost of setting the practice in a given

\footnotetext{
7 The assumption of a uniform distribution allows us to obtain closed-form solutions. In any case, the structure of the problem would not change even if a more realistic distribution were assumed.
} 
sector. Profits are therefore proportional to the net reward of a consultation, and to the number of patients who choose them. Profits (per doctor) in the two sectors are:

$$
\begin{cases}\text { Sector 1: } & \pi_{1}\left(p_{1}, c_{1}\right)=\left(p_{1}-q\right) \frac{\nu P}{\alpha M}=k\left(p_{1}-q\right) \frac{\nu}{\alpha} \\ \text { Sector } 2: & \pi_{2}\left(p_{2}, c_{2}\right)=\left(p_{2}-q\right) \frac{(1-\nu) P}{(1-\alpha) M}=k\left(p_{2}-q\right) \frac{(1-\nu)}{(1-\alpha)}\end{cases}
$$

\section{The two-sector equilibrium}

In equilibrium, patients maximize their utility under the assumption that physicians have made an optimal choice with respect to their choice of sector of practice, and physicians choose between sector 1 and sector 2 under the assumption that patients have made an optimal choice with respect to consulting a sector 1 or sector 2 specialist. Equilibrium in this market is an allocation $\left(\nu^{*}, \alpha^{*}\right)$, with $\nu^{*} \in[0,1]$ and $\alpha^{*} \in[0,1]$.

Comparative statics allow us to study the impact of changes in exogenous variables on the equilibrium endogenous variables. Yet moving from one equilibrium to another requires that patients switch from one sector to another, and that the distribution of physicians between the two sectors is reallocated until their profits once again balance each other. While patients can move without friction, physicians cannot. More specifically, changes in physician distribution are much slower, as they are determined by the number of older physicians going into retirement, and the number of new younger generations of physicians arriving into the work market. Accordingly, moving from one equilibrium to another is a lengthy process.

\subsection{The demand for health services (short-term changes)}

We first study the short-term changes to patient distribution in each sector, with a constant share of physicians in sector $1(\alpha)$. Discarding the specific cases of corner solutions with only one optimal sector, we then search for the indifferent patient between the two sectors. Let $r^{*}$ be the "threshold" reimbursement for this patient, as defined by:

$$
u\left(p_{1}, c_{1}\right)=u\left(p_{2}, c_{2}\right) \Leftrightarrow \bar{u}-c_{1}=\bar{u}-p_{2}+r^{*}-c_{2}
$$


All patients with $r<r^{*}$ prefer sector 1 over sector 2 while those with $r>r^{*}$ prefer sector 2 . The share $v^{*}$ of the patient population which prefers sector 1 is thus equal to $v^{*}=\operatorname{Pr}\left[r<r^{*}\right]$, and given that $r$ is uniformly distributed over the interval $\left[p_{1}, p_{2}\right]$, we have: $v^{*}=\frac{r^{*}-p_{1}}{\left(p_{2}-p_{1}\right)}$, or: $r^{*}=p_{1}+v^{*}\left(p_{2}-p_{1}\right)$. If we substitute this expression in the previous definition of $r^{*}$, we obtain:

$$
\begin{aligned}
\bar{u}-c_{1} & =\bar{u}-p_{2}+p_{1}+v^{*}\left(p_{2}-p_{1}\right)-c_{2} \\
& \Leftrightarrow \quad c_{1}-c_{2}=\left(1-v^{*}\right)\left(p_{2}-p_{1}\right) \\
& \Leftrightarrow \gamma k \frac{v^{*}}{\alpha}-\gamma k \frac{\left(1-v^{*}\right)}{(1-\alpha)}=\left(1-v^{*}\right)\left(p_{2}-p_{1}\right) \\
& \Leftrightarrow \quad v^{*}=\frac{\left(p_{2}-p_{1}\right)(1-\alpha)+\gamma k}{\left(p_{2}-p_{1}\right)(1-\alpha)+\gamma k\left(\frac{1}{\alpha}\right)} .
\end{aligned}
$$

Note that as $p_{2}>p_{1}$, Eq. (10) implies $c_{1}>c_{2}$ and, by definition of $c_{1}$ and $c_{2}$ (Eq. 1 and Eq. 2) that $v^{*}>\alpha$ irrespective of the values of the parameters. Note also that, for $p_{1}=p_{2}, \alpha^{*}=\nu$.

Finally, the definition of $v^{*}$ reveals an increasing relation between $v^{*}$ and $\alpha$ :

$$
\frac{\partial v^{*}}{\partial \alpha}=\frac{\gamma k}{\alpha^{2}} \frac{\left(p_{2}-p_{1}\right)(1-\alpha)^{2}+\gamma k}{\left[\left(p_{2}-p_{1}\right)(1-\alpha)+\gamma k\left(\frac{1}{\alpha}\right)\right]^{2}}>0 .
$$

The short-term effects of changes in price or the patient-to-physician ratio on $v^{*}$ are:

$$
\begin{aligned}
\frac{\partial v^{*}}{\partial p_{1}} & =(1-\alpha) \gamma k \frac{1-\left(\frac{1}{\alpha}\right)}{\left[\left(p_{2}-p_{1}\right)(1-\alpha)+\gamma k\left(\frac{1}{\alpha}\right)\right]^{2}}<0 \\
\frac{\partial v^{*}}{\partial p_{2}} & =(1-\alpha) \gamma k \frac{\left(\frac{1}{\alpha}\right)-1}{\left[\left(p_{2}-p_{1}\right)(1-\alpha)+\gamma k\left(\frac{1}{\alpha}\right)\right]^{2}}>0 \\
\frac{\partial v^{*}}{\partial \gamma k} & =\frac{\left[\left(p_{2}-p_{1}\right)(1-\alpha)\right]\left(1-\frac{1}{\alpha}\right)}{\left[\left(p_{2}-p_{1}\right)(1-\alpha)+\gamma k\left(\frac{1}{\alpha}\right)\right]^{2}}<0 .
\end{aligned}
$$

Unsurprisingly, an increase in the fee in one sector increases the attractiveness of the other sector. Note that an increase in $p_{1}$ does not change the price paid in sector 1 , as the fee is completely reimbursed by the combination of public and complementary insurance (except the one euro copayment). However, as $p_{2}$ remains constant, the rise in $p_{1}$ reduces the out-of-pocket payment for sector 2 patients and therefore contributes to the attractiveness of this sector. Note also that an increase in the patient-to-physician ratio, $k$ contributes mainly to the growth in the number of sector 2 patients. More specifically, an increase in $k$ increases the spread between the two 
congestion costs. Because $c_{1}$ rises faster than $c_{2}$ more patients are willing to consult a sector 2 physician.

In the Appendix we show that the optimal proportion of patients in sector $1, v^{*}$, is the outcome of a convergent adjustment process. If the proportion of patients in sector 1 is larger than $v^{*}$, for instance $\hat{v}>v^{*}$, it can be shown that the utility of the "switching patient" is higher in sector 2 than in sector 1. As individuals in the left neighborhood of this patient move to sector $2, v$ declines until the "switching patient" becomes indifferent between the two sectors. The opposite process occurs for $\hat{v}<v^{*}$.

\subsection{The supply for health services (long-term changes)}

We next study the physician's decision regarding which sector to work in. This decision is based on maximizing his/her profit. Physicians enter the sector that brings them the highest profits until profits in the two sectors balance each other out, $\pi_{2}=\pi_{1}$. For a given set of prices $\left(p_{1}, p_{2}\right)$, patients-to-physician ratio $(k)$ and a given proportion of patients in sector $1(v)$, the equilibrium proportion of physicians in sector 1 is the implicit solution to:

$$
\begin{aligned}
\pi_{1} & =\pi_{2} \\
& \Leftrightarrow k\left(p_{1}-q\right) \frac{\nu}{\alpha}=k\left(p_{2}-q\right) \frac{(1-\nu)}{(1-\alpha)} \\
& \Leftrightarrow \frac{(1-\nu)}{(1-\alpha)}=\frac{\nu}{\alpha} \frac{\left(p_{1}-q\right)}{\left(p_{2}-q\right)}
\end{aligned}
$$

This leads to the explicit form:

$$
\alpha^{*}=\frac{\left(p_{1}-q\right) \nu}{(1-\nu)\left(p_{2}-q\right)+\left(p_{1}-q\right) \nu}, \text { with } \alpha^{*} \in[0,1]
$$

with $d \alpha^{*} / d v>0 . .^{8}$

We can check that $\alpha^{*}$ is the outcome of a convergent process of physician allocation between the two sectors. When the proportion of doctors in sector 1 is higher than the optimal proportion

\footnotetext{
8 Note that $\alpha^{*}=0$ if $\nu=0$ and $\alpha^{*}=1$ if $\nu=1$. In both cases, patients and physicians are clustered in a single sector. The case $\nu=0$ (respectively $\nu=1$ ) implies that no patient is interested in any sector 2 offer (respectively sector 1 offer) and, as the resulting profit $\pi_{2}\left(\operatorname{resp} \pi_{1}\right)$ is zero, no physician chooses to work in sector 2 (respectively, sector 1$)$.
} 
$\alpha^{*}$, profits are higher in sector 2 than in sector 1 , and therefore the share of doctors in sector 1 must decrease in favour of sector 2. In the opposite case, when the proportion is lower than $\alpha^{*}$, we have $\pi_{1}>\pi_{2}$, and the share of doctors in sector 1 will increase and will tend towards $\alpha^{*}$.

\subsection{The equilibrium of the dual health care market}

The equilibrium proportions of physicians and patients $\left(\nu^{*}, \alpha^{*}\right)$ must simultaneously satisfy equations (12) and (20).

If we now substitute $\left[\left(1-v^{*}\right) /(1-\alpha)\right]$ for its expression in Equation (19) in Equation (12), we obtain:

$$
\begin{aligned}
& \Leftrightarrow \quad \gamma k \frac{v^{*}}{\alpha}-\gamma k \frac{v^{*}}{\alpha} \frac{\left(p_{1}-q\right)}{\left(p_{2}-q\right)}=\left(1-v^{*}\right)\left(p_{2}-p_{1}\right) \\
& \Leftrightarrow \quad v^{*}=\frac{\alpha\left(p_{2}-q\right)}{\alpha\left(p_{2}-q\right)+\gamma k} \in[0,1]
\end{aligned}
$$

Solving the equations for $\alpha^{*}$ and $\nu^{*}$, we obtain the equilibrium values:

$$
\begin{aligned}
\nu^{*} & =\frac{\left(p_{2}-q\right)\left[\left(p_{1}-q\right)-\gamma k\right]}{\left[\gamma k\left(p_{1}-q\right)+\left(p_{2}-q\right)\left[\left(p_{1}-q\right)-\gamma k\right]\right]} \\
\alpha^{*} & =\frac{\left(p_{1}-q\right)-\gamma k}{\left(p_{1}-q\right)}
\end{aligned}
$$

Note that $\alpha^{*}$ and $v^{*}$ are lower than 1 . If allowed by the organization of the healthcare market, sector 2 will always remain the optimal choice for some physicians.

On the other hand, some physicians will continue to choose sector 1 only if the price in sector 1 is large enough:

$$
\alpha^{*}>0 \Leftrightarrow p_{1}>q+\gamma k
$$

otherwise all physicians will choose to work in sector $2\left(\alpha^{*}>0 \Leftrightarrow v^{*}>0\right)$.

Hereafter, in order to rule out any possibility of a trivial equilibrium, we consider the condition in equation (25) is fulfilled.

For the above-defined long-run equilibrium values of $\alpha^{*}$ and $\nu^{*}$, we obtain the sector-specific congestion cost $c_{1}$ and $c_{2}$, and the profits per physician $\pi_{1}=\pi_{2}=\pi$. Furthermore, for a patient 
who does not change sector, his/her utility is: $u_{1}$ (resp $\left.u_{2}\right)$ :

$$
\begin{aligned}
c_{1} & =\gamma k \frac{\left(p_{2}-q\right)\left(p_{1}-q\right)}{\left(p_{1}-q-\gamma k\right)\left(p_{2}-q\right)+\gamma k\left(p_{1}-q\right)} \\
c_{2} & =\gamma k \frac{\left(p_{1}-q\right)^{2}}{\left(p_{1}-q-\gamma k\right)\left(p_{2}-q\right)+\gamma k\left(p_{1}-q\right)} \\
\pi & =k \frac{\left(p_{2}-q\right)\left(p_{1}-q\right)^{2}}{\left(p_{1}-q-\gamma k\right)\left(p_{2}-q\right)+\gamma k\left(p_{1}-q\right)} \\
u_{1} & =\bar{u}-c_{1} \\
u_{2} & =\bar{u}-p_{2}+r-c_{2}, \text { with } r \in\left[p_{1}, p_{2}\right]
\end{aligned}
$$

Finally, from a utilitarian perspective, the total utility of the patients is the sum of the utilities of all patients, of whom a share $v^{*}$ opt for sector 1 while the rest $\left(1-v^{*}\right)$ opt for the sector 2 :

$$
\begin{aligned}
U & =U_{1}+U_{2}, \text { with }\left\{\begin{array}{l}
U_{1}=P v^{*}\left(\bar{u}-c_{1}\right) \\
U_{2}=\int_{r^{*}}^{p_{2}}\left[\bar{u}-\left(p_{2}-r\right)-c_{2}\right] f(r) P d r
\end{array}\right. \\
& =P v^{*}\left(\bar{u}-c_{1}\right)+P\left(1-v^{*}\right)\left[\left(\bar{u}-c_{2}\right)-\frac{1}{2}\left(p_{2}-p_{1}\right)\left(1-\nu^{*}\right)\right]
\end{aligned}
$$

where $P$ is the patient population. For this analysis we make the assumption that $P$ is constant (accordingly, changes in $k$ are the consequence of the number of physicians varying).

\section{Properties of the solution}

In this section we analyze the consequences of changes in three variables representative of key healthcare policies:

- a change in the regulated price, $p_{1}$;

- an exogenous variation in the sector 2 price, $p_{2}$;

- a change in the economy-wide patient-to-physician ratio, $k=P / M$.

The essential endogenous variables are:

- the frequencies of patients and physicians in sector $1, \alpha^{*}$ and $v^{*}$, (and the complementary proportions in sector 2)

- the sector-specific patient-to-physician ratio and the related congestion costs, $c_{1}$ and $c_{2}$. 
- the physician profits, identical in the two sector, $\pi_{1}=\pi_{2}=\pi$.

- the utility of the representative patient in the two sectors, $u_{1}$ and $u_{2}$.

In terms of patient utility, we will first consider only the utility of 'incumbent' patients, i.e. patients who do not change sector. Obviously, these are patients relatively far from the indifferent patient $r^{*}$. If parameters change, some individuals (in the neighborhood of $r^{*}$ ) will move from one sector to another. This more complex overall variation in utility is analysed later in this article.

Table 1 summarizes the main relationships between the variables (explicit expressions are displayed in Table 2 in the Appendix).

\begin{tabular}{|l|l|l|l|l|l|l|l|}
\hline & $d \alpha^{*}$ & $d v^{*}$ & $d c_{1}$ & $d c_{2}$ & $d \pi$ & $d u_{1}$ & $d u_{2}$ \\
\hline$d p_{1}$ & + & + & - & $\begin{array}{c}-, \text { if } p_{1}<\hat{p} \\
+, \text { if } p_{1}>\hat{p}\end{array}$ & $\begin{array}{c}-, \text { if } p_{1}<\hat{p} \\
+, \text { if } p_{1}>\hat{p}\end{array}$ & + & $\begin{array}{c}+, \text { if } p_{1}<\hat{p} \\
-, \text { if } p_{1}>\hat{p}\end{array}$ \\
\hline$d p_{2}$ & 0 & + & + & - & + & - & - \\
\hline$d k$ & - & - & + & + & + & - & - \\
\hline
\end{tabular}

Table 1: Long-term effects

\subsection{Changes in $p_{1}$}

Over the long term, an increase in the regulated price $p_{1}$ attracts both more physicians and, counterintuitively, more patients to this sector. Changes in the equilibrium proportions of patients and physicians in sector 1 are:

$$
\begin{aligned}
\frac{d \alpha^{*}}{d p_{1}} & =\frac{\left(p_{1}-q\right)-\left(p_{1}-q\right)+\gamma k}{\left(p_{1}-q\right)^{2}}=\frac{\gamma k}{\left(p_{1}-q\right)^{2}}>0 \\
\frac{d v^{*}}{d p_{1}} & =\frac{\left(p_{2}-q\right)(\gamma k)^{2}}{\left[\gamma k\left(p_{1}-q\right)+\left(p_{2}-q\right)\left(p_{1}-q-\gamma k\right)\right]^{2}}>0 .
\end{aligned}
$$

Using this, we can evaluate whether the congestion cost will decrease. Indeed:

$$
\frac{d c_{1}}{d p_{1}}=-\frac{\left[\gamma k\left(p_{2}-q\right)\right]^{2}}{\left[\left(\left(p_{1}-q\right)-\gamma k\right)\left(p_{2}-q\right)+\gamma k\left(p_{1}-q\right)\right]^{2}}<0 .
$$

With fewer physicians and fewer patients in sector 2, the evolution of the congestion cost in sector 2 depends on the model's parameters. We determine:

$$
\frac{d c_{2}}{d p_{1}}=\gamma k\left(p_{1}-q\right) \frac{\left(p_{1}-q-\gamma k\right)\left(p_{2}-q\right)-\gamma k\left(p_{2}-p_{1}\right)}{\left[\left(p_{1}-q-\gamma k\right)\left(p_{2}-q\right)+\gamma k\left(p_{1}-q\right)\right]^{2}}
$$


The sign of this derivative is the sign of expression $\left[\left(p_{1}-q-\gamma k\right)\left(p_{2}-q\right)-\gamma k\left(p_{2}-p_{1}\right)\right]$. If we define

$$
\hat{p}=\frac{q\left(p_{2}-q\right)+\gamma k\left(2 p_{2}-q\right)}{\left(p_{2}-q+\gamma k\right)}
$$

then it turns out that:

$$
\left\{\begin{array}{l}
\frac{d c_{2}}{d p_{1}} \leq 0 \text { for } p_{1} \leq \hat{p} \\
\frac{d c_{2}}{d p_{1}}>0 \text { for } p_{1}>\hat{p}
\end{array} .\right.
$$

We argued that a two-sector equilibrium exists only for $p_{1}>q+\gamma k$ (condition 25). Given the sectorial constraint $p_{2}>p_{1}$ (see above), we can check that $(q+\gamma k)<\hat{p}<p_{2}$. This means that the turning point is well located within the interval of definition of $p_{1}$.

As long as $p_{1}$ is initially relatively small, an increase in this price will reduce the congestion cost in sector 2; however, this effect is reversed for a relatively large $p_{1}$. The congestion cost in sector 2 is the lowest when $p_{1}=\hat{p}_{1} \cdot{ }^{9}$

The effect of a higher $p_{1}$ on the variation in profits is related to the variation of the congestion cost in the sector 2 :

$$
\frac{d \pi}{d p_{1}}=k\left(p_{2}-q\right)\left(p_{1}-q\right) \frac{\left(p_{1}-q\right)\left(p_{2}-q\right)-\gamma k\left(2 p_{2}-q-p_{1}\right)}{\left[\left(p_{1}-q-\gamma k\right)\left(p_{2}-q\right)+\gamma k\left(p_{1}-q\right)\right]^{2}}
$$

We can easily check whether $\frac{d \pi}{d p_{1}}>0$ if $\frac{d c_{2}}{d p_{1}}>0$ and $\frac{d \pi}{d p_{1}}<0$ if $\frac{d c_{2}}{d p_{1}}<0$.

The economic mechanisms driving these changes are relatively complex. We remind the reader that sector 1 patients do not pay the fee $p_{1}$, as it is assumed that this cost is fully covered by basic and complementary insurance. However, a larger $p_{1}$ reduces the out-of-pocket payment for sector 2 patients, and consequently attracts patients to this sector. In turn, this induces a rise in the congestion cost in sector $2, c_{2}$. At the same time, as $p_{1}$ increases, the $\alpha^{*}$ value which ensures the long-term equality of profit increases (see Eq. 32); at a constant $\alpha$, this implies that $\pi_{1}>\pi_{2}$. In the long term, all other things being equal, higher profits in sector 1 attract more physicians

\footnotetext{
9 This shortest waiting time is not necessarily socially optimal, given that a higher $p_{1}$ could further reduce waiting time in sector 1 .
} 
to this sector, $\frac{d \alpha^{*}}{d p_{1}}>0$. The congestion cost $c_{1}$ continues to decline, attracting more patients to sector 1 , which limits and may even offset the initial increase in the congestion cost $c_{2}$.

The long term effect of a higher $p_{1}$ on profits per physician (identical in the two sectors) is undetermined. An increase in $p_{1}$ prompts more physicians and patients to choose the sector 1 . The effect on profits may be positive or negative, depending on the initial situation, and the elasticity of sector choice of the two agents. If following the increase in $p_{1}$ there are less patients per physician in sector 2 (the profit margin in sector 2 being constant), profits per physician decline. On the other hand, if there are more patients per physician in sector 2 , the profit per physician increases.

Our analysis therefore highlights that an increase in the regulated price $p_{1}$ does not mechanically lead to higher profits for the medical profession. This result indicates that there is no simple solution to the question of how to increase physicians' incomes.

In terms of utility change (for incumbent patients), for a sector 1 patient we have:

$$
\frac{d u_{1}}{d p_{1}}=-\frac{d c_{1}}{d p_{1}}>0
$$

Because sector 1 patients do not pay the price $p_{1}$, and benefit from a lower congestion cost as $p_{1}$ increases, the utility of the patient who remains with a physician in sector 1 will increase as long as $p_{1}$ increases.

In sector 2 , we study the variation in the utility of a patient who does not change sector when $p_{1}$ changes. The utility of this patient is $u_{2}=\bar{u}-\left(p_{2}-r\right)-c_{2}$. His/her variation in utility therefore depends only on the variation in congestion cost, the latter being related to the derivatives in Eq. (37) as follows:

$$
\frac{d u_{2}}{d p_{1}}=-\frac{d c_{2}}{d p_{1}}
$$

The utility first increases in $p_{1}$, reaching a maximum when $p_{1}=\hat{p}_{1}$, and then declines.

When considering the total utility $U$, any changes in parameters lead to a complex effect, as both individual utilities and the numbers of patients in each sector may change. For instance, 


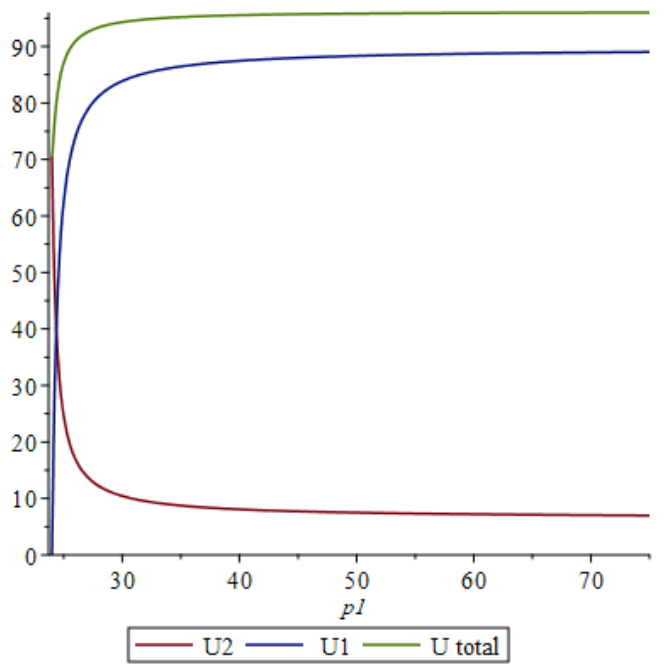

Figure 2: Utility with respect to $p_{1}$

if fewer patients remain in sector 2 , total utility in sector 2 can decline even if individual utility increases. To address this complexity, we present here a numerical simulation here, representing total utility in sector 1 , in sector 2 and overall, when $p_{1}$ varies. Invariant parameters are $u=100$, $q=20, p_{2}=75, k=8, \gamma=1 / 2$. When $p_{1}$ varies between $(\gamma k+q)=24$ and $p_{2}$, increases in $p_{1}$ lead to an increase in the sector 1's overall utility.

For $p_{1}<\hat{p}=27.45$, the utility of an incumbent patient in sector 2 increases with $p_{1}$. However, the simulation shows that the overall utility of the patients in the sector 2 systematically falls as the sector shrinks. Not only doctors leave the sector 2 , but so do some patients.

Overall utility nonetheless increases in $p_{1}$.

\subsection{Changes in $p_{2}$}

As mentioned in the introduction, recent French government regulations have strived to encourage sector 2 physicians to cap their fees. A decisive step was taken in 2017 with the implementation of the OPTAM agreement (Option Pratique Tarifaire Maitrisée). Physicians who join this scheme commit themselves to charging a maximum fee of twice the regulated price for a specific service. As of September 2019, 30\% of sector 2 physicians had signed up to this agreement. 
The effects of these regulations on changes in $p_{2}$ can be analysed in the same way we analysed changes in $p_{1}$.

From Equation (15) we see that in the short term, any price increase reduces the number of patients in sector 2 and increases sector 1's congestion cost, while profits increase in both sectors: in sector 1 this increase is due to the higher number of patients per physician, while in sector 2 it stems from the rise in physician fees. Changes in profits are equal in both sectors. Accordingly, changes in $p_{2}$ do not alter the distribution of physicians in the two sectors.

In the long term, Eq. (24) reveals that the equilibrium number of physicians in sector 1 is not related to $p_{2}$.

$$
\frac{d \alpha^{*}}{d p_{2}}=0
$$

Long-term effects are therefore similar to short-term effects.

The effect of an increase in $p_{2}$ on the number of patients migrating to sector 1 (i.e., leaving sector 2) is positive.

$$
\frac{d v^{*}}{d p_{2}}=\frac{\left(p_{1}-q-\gamma k\right) \gamma k\left(p_{1}-q\right)}{\left[\gamma k\left(p_{1}-q\right)+\left(p_{2}-q\right)\left[\left(p_{1}-q\right)-\gamma k\right]\right]^{2}}>0
$$

Since $\alpha$ is not affected, this implies a higher congestion cost in sector 1 , and an increase in the congestion $\operatorname{cost} c_{1}$ :

$$
\frac{d c_{1}}{d p_{2}}=\frac{\left[\gamma k\left(p_{1}-q\right)\right]^{2}}{\left[\left(\left(p_{1}-q\right)-\gamma k\right)\left(p_{2}-q\right)+\gamma k\left(p_{1}-q\right)\right]^{2}}>0
$$

There is a reduction in $c_{2}$ :

$$
\frac{d c_{2}}{d p_{2}}=-\gamma k \frac{\left(p_{1}-q\right)^{2}\left(p_{1}-q-\gamma k\right)}{\left[\left(p_{1}-q-\gamma k\right)\left(p_{2}-q\right)+\gamma k\left(p_{1}-q\right)\right]^{2}}<0
$$

And the profit per physician goes up:

$$
\frac{d \pi}{d p_{2}}=\frac{\left(p_{1}-q\right)}{\alpha} \frac{d v^{*}}{d p_{2}}>0
$$




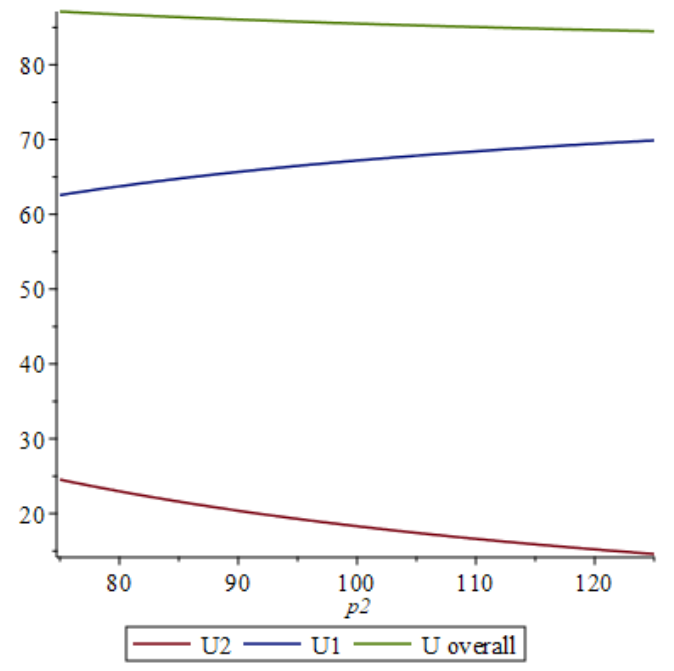

Figure 3: Utility with respect to $p_{2}$

The variation in utility of the sector 1 incumbent patients depends on the change in congestion costs; it lowers when the price $p_{2}$ increases because sector 2 patients flee to sector 1 .

$$
\frac{d u_{1}}{d p_{2}}=-\frac{d c_{1}}{d p_{2}}<0
$$

For the sector 2 individual who has to pay the out-of-pocket payment $\left(p_{2}-r\right)$, the utility variation is a combination of a higher price, and a lower congestion cost. Under our assumptions, the negative price effect prevails over the later:

$$
\frac{d u_{2}}{d p_{2}}=-1-\frac{d c_{2}}{d p_{2}}<0
$$

The overall effect on utility of a change of $p_{2}$ is illustrated by the following numerical simulation, representing utility in both sectors when $p_{2}$ varies. As in the previous simulation, invariant parameters are $u=100, q=20, k=8, \gamma=1 / 2$. Furthermore, we assume that $p_{1}=25$.

The increase in $p_{2}$ brings about a decline in overall utility in sector 2 . However, unlike the findings from the previous analysis (for $p_{1}$ ), it leads to an increase in overall utility of the patients in sector 1, because this sector is growing. However, even if the changes in both sectors offset each other, total utility declines when $p_{2}$ increases.

To summarize, an increase in $p_{2}$ will push up the out-of-pocket payment and prompt patients 
with less generous health insurance coverage to migrate to sector 1 . This will reduce congestion in sector 2, which in turns limits the outward flow. With the additional patients (who have migrated from sector 2), the congestion cost in sector 1 increases, which makes sector 1 less attractive. One would expect that the increase in $p_{2}$ would attract physicians to sector 2. However, with our linear function, this "intensive margin" effect is offset by the lower number of patients (a reduction in the extensive margin).

Profits increase in sector 1 because the number of patients per physician increases. In sector 2, profits increase despite the reduced number of patients per doctor, because the margins are now bigger.

The utility of incumbent patients declines in both sectors, driven by a higher congestion cost in sector 1 , and by the higher out-of-pocket payment not fully compensated by the lower congestion cost in sector 2. Overall utility decreases slightly as $p_{2}$ increases.

\subsection{Changes in $k$}

Changes in the economy-wide patients-to-physician ratio, $k=P / M$, are partially the result of structural changes. In particular, population aging in the developed world is contributing to increase $P$, the number of persons needing an increased amount of healthcare services. Policies that allow for an increase in the number of practicing physicians by increasing the number of physicians trained in higher education institutions and easing immigration restrictions on healthcare professionals - can increase $M$ (and reduce $k$ ).

In France, successive governments from 1970 onward adopted a numerus clausus (i.e., fixed number or quota) approach to medical education. However, over time this led to a shortage of physicians in many specialist areas, with a peak shortage in the mid-1990s. Since then, numbers of new trainee physicians have increased every year, but the same logic of education quotas remains. From 2020-2021, this policy of education quotas will be replaced with more flexible management 
of the numbers of places in higher education for medical-related fields. ${ }^{10}$ This change will be tantamount to an increase in $M$, and a reduction in $k$.

In the following analysis, we will focus on the effect of a reduction in the more general variable $(\gamma k)$

$$
\frac{\partial v^{*}}{\partial \gamma k}=\frac{\left[\left(p_{2}-p_{1}\right)(1-\alpha)\right]\left(1-\frac{1}{\alpha}\right)}{\left[\left(p_{2}-p_{1}\right)(1-\alpha)+\gamma k\left(\frac{1}{\alpha}\right)\right]^{2}}<0
$$

In our model, a reduction in $k$ (or in $\gamma k$ ) leads to a short term decrease in the number of patients in sector 2. In the long term, this leads to a decrease in profits in this sector and makes the sector less attractive for physicians.

$$
\frac{d \alpha^{*}}{d \gamma k}=-\frac{1}{\left(p_{1}-q\right)}<0
$$

As congestion increases in sector 2 (because of fewer physicians), this leads to an increase in the number of patients in sector 1 , and the number of patients in sector 2 decreases.

$$
\frac{d v^{*}}{d \gamma k}=-\frac{\left(p_{2}-q\right)\left(p_{1}-q\right)^{2}}{\left[\gamma k\left(p_{1}-q\right)+\left(p_{1}-q-\gamma k\right)\left(p_{2}-q\right)\right]^{2}}<0 .
$$

From the two previous equations, we can infer that a change in prompts the number of physicians and patients in a given sector to move in the same direction.

The congestion cost decreases in both sectors (there are fewer patients per doctor on average).

$$
\begin{aligned}
\frac{d c_{1}}{d k} & =\frac{\left[\left(p_{1}-q\right)\left(p_{2}-q\right)\right]^{2}}{\left[\left(\left(p_{1}-q\right)-\gamma k\right)\left(p_{2}-q\right)+\gamma k\left(p_{1}-q\right)\right]^{2}}>0 \\
\frac{d c_{2}}{d k} & =\frac{\left(p_{1}-q\right)^{3}\left(p_{2}-q\right)}{\left[\left(p_{1}-q-\gamma k\right)\left(p_{2}-q\right)+\gamma k\left(p_{1}-q\right)\right]^{2}}>0 .
\end{aligned}
$$

Yet the change in the congestion cost is lower in sector 2 than in sector $1\left(\frac{d c_{2}}{d k}<\frac{d c_{1}}{d k}\right)$.

With fewer patients per doctor, profits in the healthcare sector decline:

$$
\frac{d \pi_{1}}{d k}=\frac{\left(p_{1}-q\right)^{3}\left(p_{2}-q\right)^{2}}{\left[\left(\left(p_{1}-q\right)-\gamma k\right)\left(p_{2}-q\right)+\gamma k\left(p_{1}-q\right)\right]^{2}}>0
$$

10 Press release of the French Government, May 18, 2020 


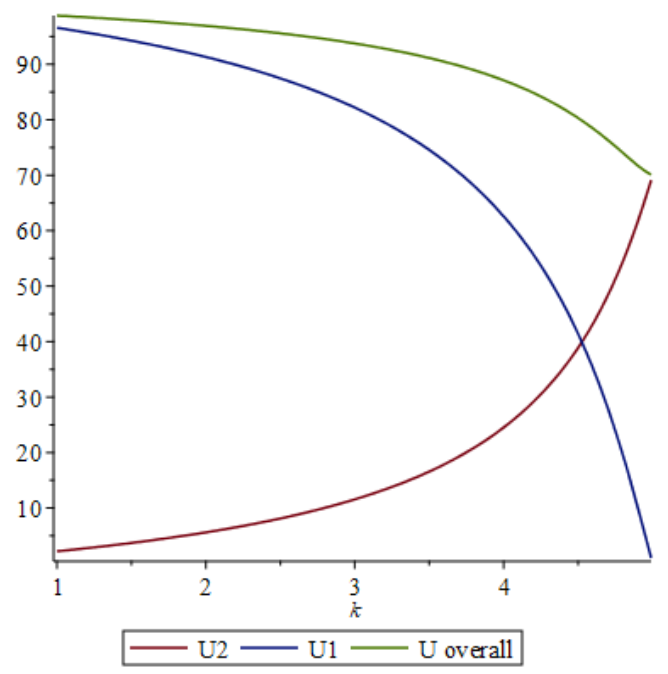

Figure 4: Utility with respect to $k$

Individual utility increases in both sectors, with lower congestion costs, at unchanged prices.

Finally, Figure 4 illustrates how total utility varies when the number of doctors varies (i.e., when $k$ varies) with $u=100, q=20, k=8, \gamma=1 / 2, p_{1}=25$ and $p_{2}=75$. Utility is the largest when the number of physicians is the highest (i.e., the lowest $k$ ). If $k$ increases, total utility declines and vice-versa. With more physicians, $k$ declines and total utility increases. However, a reduction in $k$ means an increase in overall utility of the patients in sector 1 , but penalizes overall utility of patients in sector 2 .

To summarize, a reduction in the number of patients per physician $k$ will push down congestion costs in both sectors. However, the congestion cost declines relatively less in sector 2. Profits decrease given the lower number of patients per physician, while the utility of incumbent patients increases.

In the current context where the French government continues to declare its desire to attract more talent into the medical profession, any reduction in profit could hamper achieving this goal. 


\section{Conclusion}

This paper introduces a two-sector equilibrium model to investigate the dual-legal structure of the French market for specialized outpatient services. In the model, the two sectors differ in terms of fees, insurance coverage, and, as an original contribution to the literature, number of patients a physician meets over a standard period of working time. The number of patients per physician in each sector is endogenously determined, as the related congestion cost enters the utility function of the patient. Although our model focusses on the specific case of France, it can be applied to any healthcare system with a balance billing design where full reimbursement is granted for a basic service, and where out-of-pocket payments allow the patient to benefit of a better non-medical quality of care (e.g., a private room in hospital, longer consultations, reduced waiting times).

Our model presents a unique, stable, non-trivial equilibrium defined as the equilibrium proportion of physicians and patients in each sector. While many results reflect what intuitive reasoning would suggest, some are more challenging to understand.

For instance, over the long term, and as long as $p_{1}<\hat{p}$, an increase in the regulated price $p_{1}$ cuts congestion in both sectors due to the reallocation of physicians and patients (the economywide patient-to-physician ratio being invariant). Patient utility in both sectors increases while the physician profits decrease, meaning that the global cost of healthcare also decreases.

From a policy perspective, a rise in $p_{1}$ (as long as $p_{1}<\hat{p}$ ) brings about greater patient welfare at a lower social cost. Furthermore, an increase in the regulated price $\left(p_{1}\right)$ fosters the size of the regulated sector (sector 1) relative to sector 2. An increase in the regulated price attracts not only more physicians but also more patients to sector 1 . However, the effect of an increase of $p_{1}$ on a physician's income (in both sectors) depends on the specific parameters of the problem. A situation where a higher price for the service leads to lower physician income in the long term cannot be ruled out. The French government, which continues to indicate its desire to attract more talent to the medical profession, should keep this possibility in mind. 
In our model, a change in $p_{2}$ has no effect on the relative number of physicians in the two sectors. For physicians in sector 2 , the increase in $p_{2}$ leads to higher physician profits per patient, but as patients leave sector 2 for sector 1, profits for physicians in the latter increase in the same proportions. As profits remain the same in both sectors, physicians have no incentive to change sector. This result is driven by our study assumptions and should not be considered general. However, the model emphasizes the existence of two opposite effects on a physician's choice of sector, in the case of a change in the unregulated price $p_{2}$. Even in more general contexts, these two opposite effects would still be at work, explaining why a change in $p_{2}$ could only have a second order effect on the distribution of physicians among the two sectors. One important policy implication is that the recent steps by the French government to encourage physicians to cap sector 2 service fees, might have only a limited impact on the number of physicians deciding to work in that sector.

Finally, increasing the number of available physicians by training more of them (i.e., a lower $k$ ) would increase the number of physicians who decide to work in sector 1 . One might expect that this increase would either have a neutral impact on the sector sizes or that new physicians would be more attracted by the higher fees (and therefore perceived net higher profits) in sector 2 . In our model, both the proportions of patients and physicians in sector 1 increase when the overall number of physicians increases. Congestion declines in the two sectors, but this decline is faster in sector 1 than in sector 2. Furthermore, reforms leading to an increased number of physicians in turn increase patient utility and reduce profits. It is likely that the medical profession will support moderate increases in the number of physicians proportional to the increase in the number of patients, but will resist larger increases. Certainly, at some point, the planned increase in the numbers of trained physicians in France might enter conflict with the same government's 2020 promise to raise incomes in the medical profession. 


\section{References}

Bardey, D., H. Cremer, and J.-M. Lozachmeur, 2014. Competition in two-sided markets with common network externalities. Review of Industrial Organization 44 (4): 327-345.

Besancenot, D. and R. Vranceanu, 2004. Quality and price dispersion in an equilibrium search model, Journal of Economics and Business, 56 (2), 99-116.

Brekke, K. R., Siciliani, L. and O. R. Straume, 2012. Quality competition with profit constraints. Journal of Economic Behavior and Organization, 84 (2), 642-659.

Brekke, Kurt R., Luigi Siciliani, and Odd Rune Straume, 2008. Competition and waiting times in hospital markets. Journal of Public Economics 92 (7): 1607-1628.

Besancenot, D. and Vranceanu R., 2017. An equilibrium search model of the French market for medical services, ESSEC Working Paper 1709.

Calcoen, P., and Van de Ven W. P.M.M., 2019. Supplementary physicians' fees: a sustainable system? Health Economics, Policy and Law, 14, (1): 40-60.

Coudin E., Pla A., and Samson A. L., 2015. GPs' response to price regulation : evidence from a nationwide French reform. Health Economics, 24, (9): 1118-1130.

Clerc, I., L'Haridon, O., Paraponaris, A., Protopopescu, C. and Ventelou B., 2012. Fee-forservice payments and consultation length in general practice: a work-leisure trade-off model for French GPs. Applied Economics, 44, (25): 3323-3337.

Dormont B., and Péron M., 2016. Does health insurance encourage the rise in medical prices? A test on balance billing in France. Health Economics, 25: 1073-1089.

DREES, 2019. Les Dépenses de Santé en 2018, collection Panoramas de la Drees, Paris, 2019 .

DREES, 2006. La durée des séances des médecins généralistes, DREES Etudes et Résultats, nr 481.

Einav, Liran, Amy Finkelstein, and Heidi Williams. 2016. Paying on the margin for medical care: Evidence from breast cancer treatments." American Economic Journal: Economic Policy 8(1): 52-79)

Feldman R., and Sloan F., 1988. Competition among physicians, revisited. Journal of Health Politics, Policy and Law, 13: 239-261.

Glazer J., McGuire T.G., 1993. Should physicians be permitted to balance bill patients? Journal of Health Economics, 12 (3): 239-258.

Godager, Geir, and Daniel Wiesen, 2013. Profit or patients' health benefit? Exploring the heterogeneity in physician altruism. Journal of Health Economics 32, 6: 1105-1116.

Gravelle H., Scott A., Sivey P., and Yong J., 2016. Competition, prices and quality in the market for physician consultations. Journal of Industrial Economics, 64, (1): 135-169.

Hoel, Michael, Erik Magnus Sæther, 2003, Public health care with waiting time: the role of supplementary private health care, Journal of Health Economics, 22, Issue 4: 599-616

Hutton, Catherine, and Jane Gunn, 2007. Do longer consultations improve the management of psychological problems in general practice? A systematic literature review. BMC Health Services Research 7.1: 71. 
Jelovac, I., 2015. Physicians' balance billing, supplemental insurance and access to health care, International Journal of Health Economics and Management, 15, (2): 269-280.

Kifmann M. and Scheuer F., 2011. Balance billing: the patients' perspective. Health Economics Review, 1 (1): 1-14.

Lecluyse A., Van de Voorde C., De Graeve D., Schokkaert E., and Van Ourti T., 2009. Hospital supplements in Belgium: price variation and regulation. Health Policy, 92, (2): 276-287.

Mitchell J. B., Cromwell J., 1982. Physician behavior under the Medicare assignment option. Journal of Health Economics, 1, 245-264

Mu, C., De Abreu Lourenco, R., van Gool, K., and Hall, J., 2018. Is low-priced primary care bad for quality? Evidence from Australian general practice. Applied Economics, 5, (5): 475-491.

Savage E. and Jones G., 2004. An analysis of the General Practice Access Scheme on GP incomes, bulk-billing and consumer copayments. Australian Economic Review, 37, (1): 31-40

Wilson, Andrew, and Susan Childs, 2002. The relationship between consultation length, process and outcomes in general practice: a systematic review. British Journal of General Practice 52, 485: 1012-1020.

Zuckerman S. and Holahan J., 1991. The role of balance billing in medicare physician payment reform. In Regulating Doctors' Fees: Competition, Benefits and Controls under Medicare. Edited by: HE Frech, III. AEI Press, Washington, DC: 143-169.

\section{A Appendix}

\section{A.1 Long-term partial derivatives}

The analysis is carried out under the condition $p_{1}>(q+\gamma k)$.

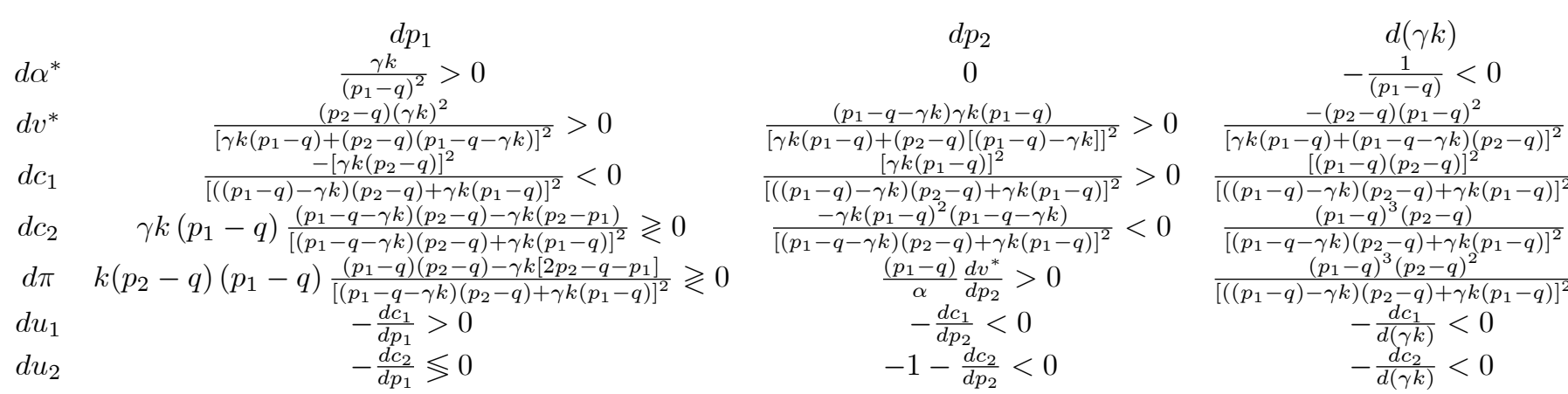

Table 2: Long-term effects, partial derivatives 


\section{A.2 Existence of a stable, non-trivial solution}

The equilibrium proportion of patients $v^{*}$ (and the implicit compensation $r^{*}$ of the "switching" patient) was defined by:

$$
\begin{aligned}
\bar{u}-c_{1}\left(v^{*}\right) & =\bar{u}-c_{2}\left(v^{*}\right)-\left(1-v^{*}\right)\left(p_{2}-p_{1}\right) \\
& \Leftrightarrow \quad c_{1}\left(v^{*}\right)-c_{2}\left(v^{*}\right)=\left(1-v^{*}\right)\left(p_{2}-p_{1}\right) \\
& \Leftrightarrow \gamma k \frac{v^{*}}{\alpha}-\gamma k \frac{\left(1-v^{*}\right)}{(1-\alpha)}=\left(1-v^{*}\right)\left(p_{2}-p_{1}\right)
\end{aligned}
$$

Leading us to write:

$$
v^{*}(\alpha)=\frac{\left(p_{2}-p_{1}\right)(1-\alpha)+\gamma k}{\left(p_{2}-p_{1}\right)(1-\alpha)+\gamma k\left(\frac{1}{\alpha}\right)}
$$

with $v^{*}(0)=0$. Let us denote this curve by $s s^{\prime}$ (see Figure 4 ).

We show that $v^{*}(\alpha)$ is concave and increasing in $\alpha$.

$$
\begin{aligned}
\frac{\partial v^{*}}{\partial \alpha} & =\frac{\gamma k}{\alpha^{2}} \frac{\left(p_{2}-p_{1}\right)(1-\alpha)^{2}+\gamma k}{\left[\left(p_{2}-p_{1}\right)(1-\alpha)+\gamma k\left(\frac{1}{\alpha}\right)\right]^{2}}>0 \\
\frac{\partial^{2} v^{*}}{\partial \alpha^{2}} & =\gamma k\left(p_{2}-p_{1}\right) \frac{-\left(p_{2}-p_{1}\right)(1-\alpha)^{2}-2(1-\alpha) \gamma k-\gamma k(1-2 \alpha)}{\left[\left(p_{2}-p_{1}\right)(1-\alpha) \alpha+\gamma k\right]^{4}}<0
\end{aligned}
$$

At the origin,

$$
\left[\frac{\partial v^{*}}{\partial \alpha}\right]_{\alpha=0}=\frac{\left(p_{2}-p_{1}\right)+\gamma k}{\gamma k}>1
$$

To study convergence, let us consider a desequilibrium situation in which for an allocation of $\hat{v}$ patients in sector 1 and $(1-\hat{v})$ in sector 2 , the "switching patient" (with a reimbursement $\hat{r}$ ) has a larger utility in sector 2 than in sector 1 ; there must then be some individuals in his "left neighborhood" that could switch to sector 2 as well, i.e., the frequency of patients in sector 1 should decline. We check that $\bar{u}-c_{1}(\hat{v})<\bar{u}-c_{2}(\hat{v})-(1-\hat{v})\left(p_{2}-p_{1}\right) \Leftrightarrow \hat{v}>v^{*}$, patients move 
to sector 2 , until $v^{*}$ is reached.

$$
\begin{aligned}
\bar{u}-c_{1}(\hat{v}) & <\bar{u}-c_{2}(\hat{v})-(1-\hat{v})\left(p_{2}-p_{1}\right) \\
c_{2}(\hat{v})-c_{1}(\hat{v}) & >(1-\hat{v})\left(p_{2}-p_{1}\right) \\
\gamma k \frac{\hat{v}}{\alpha}-\gamma k \frac{(1-\hat{v})}{(1-\alpha)} & >(1-\hat{v})\left(p_{2}-p_{1}\right) \\
\hat{v}\left[\frac{\gamma k}{\alpha}+\left(p_{2}-p_{1}\right)(1-\alpha)\right] & >(1-\alpha)\left(p_{2}-p_{1}\right)+\gamma k \\
\hat{v} & >v^{*}
\end{aligned}
$$

Patients must move to sector 2 , the frequency of patients in sector 1 declines, until $v^{*}(\alpha)$ is reached.

We turn now to the profit indifference condition.

For a given $v$, the equilibrium frequancy of physicians is a function:

$$
\alpha^{*}(v)=\frac{\left(p_{1}-q\right) \nu}{(1-\nu)\left(p_{2}-q\right)+\left(p_{1}-q\right) \nu}
$$

with $\alpha^{*}(0)=0$. Let us denote by $n n^{\prime}$ the curve $\alpha^{*}(v)$.

We can show it is increasing and concave:

$$
\begin{aligned}
\frac{\partial \alpha^{*}}{\partial v} & =\frac{\left(p_{1}-q\right)\left(p_{2}-q\right)}{\left[(1-\nu)\left(p_{2}-q\right)+\left(p_{1}-q\right) \nu\right]^{2}}>0 \\
\frac{\partial^{2} \alpha^{*}}{\partial v^{2}} & =-\frac{\left(p_{1}-q\right)\left(p_{2}-q\right)\left[p_{2}-p_{1}\right]}{\left[(1-\nu)\left(p_{2}-q\right)+\left(p_{1}-q\right) \nu\right]^{4}}<0
\end{aligned}
$$

Also,

$$
\left[\frac{\partial \alpha^{*}}{\partial v}\right]_{v=0}=\frac{\left(p_{1}-q\right)}{\left(p_{2}-q\right)}<1
$$

To study convergence, let us assume that the proportion of physicians in sector one is larger than the equilibrium proportion, $\alpha>\alpha^{*}$. Then $\pi_{1}<\pi_{2}$, thus $\alpha$ declines, to converge towards $\alpha^{*}$.

The problem has a non-trivial solution if $s s^{\prime}$ and $n n^{\prime}$ cross for $v^{*}>0$ and $\alpha^{*}>0$. We show that such a solution exists and it is unique.

Both $s s^{\prime}$ and $n n^{\prime}$ have 0 as the origin. In the $(O \alpha, O v)$ plane, $s s^{\prime}$ is concave, while $n n^{\prime}$ is convex. We can check (see Figure 5) that the two curves cross once if, at the origin, the slope of $s s^{\prime}$ is smaller than the slope of $n n^{\prime}$. This can be easily verified: 


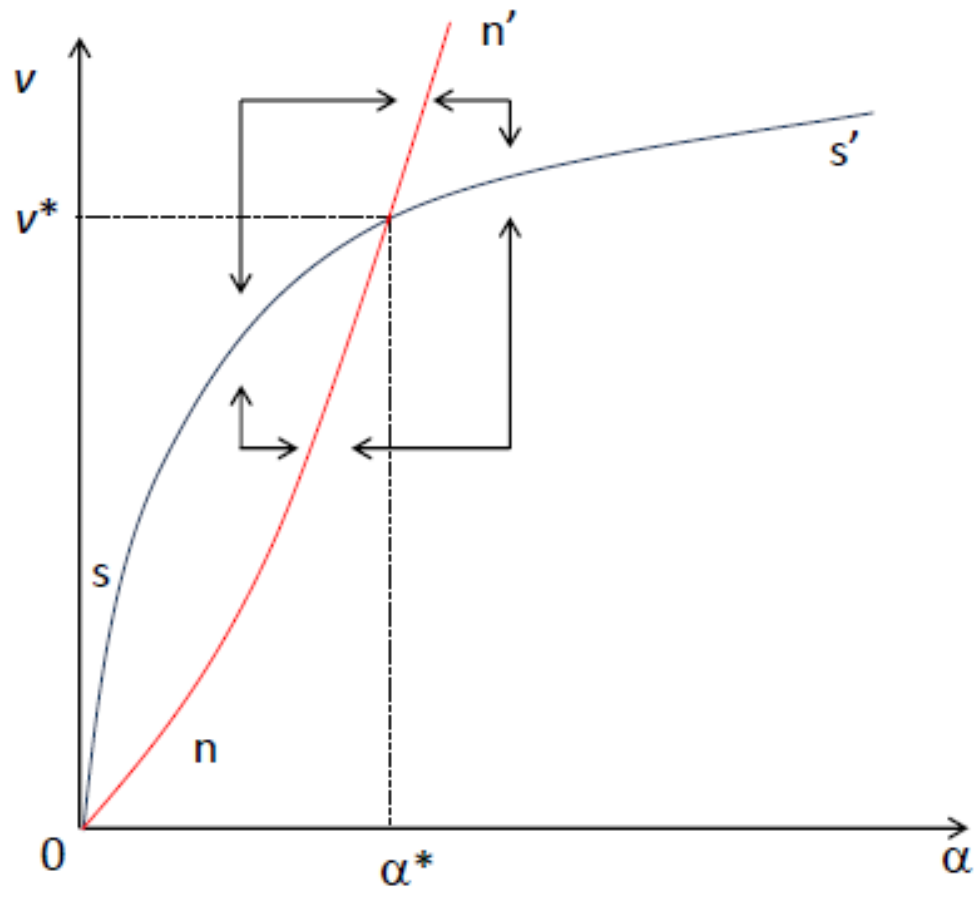

Figure 5: Equilibrium proportions of patients and physicians.

$$
\begin{gathered}
{\left[\frac{\partial v^{*}}{\partial \alpha}\right]_{s s^{\prime}, \alpha=0}=\frac{\left(p_{2}-p_{1}\right)+\gamma k}{\gamma k}>1} \\
{\left[\frac{\partial \alpha^{*}}{\partial v}\right]_{n n^{\prime}, v=0}=\frac{\left(p_{1}-q\right)}{\left(p_{2}-q\right)} \Leftrightarrow\left[\frac{\partial v}{\partial \alpha}\right]_{n n^{\prime}, \alpha=0}=\frac{\left(p_{2}-q\right)}{\left(p_{1}-q\right)}} \\
{\left[\frac{\partial v}{\partial \alpha}\right]_{n n^{\prime}, \alpha=0}<\left[\frac{\partial v^{*}}{\partial \alpha}\right]_{s s^{\prime}, \alpha=0}} \\
\frac{\left(p_{2}-q\right)}{\left(p_{1}-q\right)}<\frac{\left(p_{2}-p_{1}\right)+\gamma k}{\gamma k} \\
\gamma k<\left(p_{1}-q\right) \Leftrightarrow \alpha^{*}>0
\end{gathered}
$$




\section{ESSEC}

BUSINESS SCHOOL

ESSEC Business School

3 avenue Bernard-Hirsch

CS 50105 Cergy

95021 Cergy-Pontoise Cedex

France

Tel. +33 (0)134433000

www.essec.edu

\section{ESSEC Executive Education}

CNIT BP 230

92053 Paris-La Défense

France

Tel. +33 (0)1 46924900

www.executive-education.essec.edu

ESSEC Asia-Pacific

5 Nepal Park

CONTACT

Singapore 139408

RESEARCH CENTER

Tel. +6568849780

research@essec.edu

ESSEC | CPE Registration number 200511927D

Period of registration: 30 June 2017 - 29 June 2023

Committee of Private Education (CPE) is part of SkillsFuture Singapore (SSG)

\section{ESSEC Africa}

Plage des Nations - Golf City

Route de Kênitra - Sidi Bouknadel (Rabat-Salê)

Morocco

Tel. +212 (0)5 37824000

www.essec.edu 